\title{
Hormone Replacement Therapy: Lebanese Women's Awareness, Perception, and Acceptance
}

\author{
A. Anastasia Salame, Mohammad J. Jaffal, Fatin Khalifeh, Dalia Khalife, \\ and Ghina Ghazeeri iD \\ Department of Obstetrics and Gynecology, American University of Beirut Medical Center, P.O. Box 113-6044, Beirut, Lebanon \\ Correspondence should be addressed to Ghina Ghazeeri; gg02@aub.edu.lb
}

Received 28 July 2019; Revised 7 May 2020; Accepted 15 May 2020; Published 16 June 2020

Academic Editor: W.T. Creasman

Copyright (C) 2020 A. Anastasia Salame et al. This is an open access article distributed under the Creative Commons Attribution License, which permits unrestricted use, distribution, and reproduction in any medium, provided the original work is properly cited.

\begin{abstract}
Objectives. Hormone replacement therapy (HRT) had been the gold standard for the treatment of menopausal symptoms until the publication of the World Health Initiative (WHI) study. After the WHI study, the use of HRT changed among the physicians and patients all over the world despite newer more reassuring data. This study aimed to investigate the knowledge and attitudes of women towards HRT and the factors affecting it for better counseling. Study design. A clinic-based cross-sectional study using a survey was offered to women aged 40 years and above coming to the women's health center at the American University of Beirut Medical Center (AUBMC) from October $1^{\text {st }}, 2017$, till March $31^{\text {st }}, 2018$. The questionnaire included questions about demographics and menopausal symptoms in addition to knowledge and attitudes towards menopause and HRT. Main outcome measures. Our main hypothesis was that women would be aware of HRT as a treatment modality; however, the majority would have a negative attitude towards its usage. Results. The response rate was $87.8 \%$. Seventy-three percent of the respondents had already heard about HRT with $57.9 \%$ supporting the use of HRT; however, $47.9 \%$ did not know when to use it. The significant predictor for having heard about HRT and a positive attitude towards HRT were having HRT prescribed as a part of treatment and employment status, respectively. Conclusions. Lebanese women are aware of HRT as a treatment option; however, a lack of both proper information and positive attitude towards HRT use was noted.
\end{abstract}

\section{Introduction}

Menopause results from the natural variation in the hormonal profile that eventually results in the cessation of the ovarian endocrine function referred to as the climacteric change $[1,2]$. Women might experience mood disturbances, depression, hot flashes, vasomotor symptoms, recurrent urinary tract infections, vaginal atrophy with alteration of the sexual life, and libido, as well as osteoporosis and cardiovascular disease [3].

Hormone replacement therapy (HRT), in the form of estrogen alone or combined estrogen and progesterone formulations, has been widely used to treat menopausal symptoms to improve women's quality of life, control their climacteric symptoms, and prevent osteoporosis [4]. However, the publication of Women's Health Initiative
(WHI) controlled trial results in 2002 changed the medical and public point of view towards HRT. The WHI study assessed the benefits and risks of HRT in advanced age menopausal women and came to conclude that even though HRT decreased fracture rates and vasomotor symptoms in postmenopausal patients, it did not increase their quality of life. Moreover, it showed unexpectedly that HRT use leads to an increased incidence of cardiac events, stroke, deep venous thrombosis, and breast cancer which led to the premature closure of the study [5]. In the direct post-WHI era and being affected by the WHI results as well as by the American College of Obstetrics and Gynecology (ACOG) [6] and the U.S. Preventive Services Task Force recommendations, health care providers and obstetricians started to avoid using HRT offering menopausal patients less effective alternative treatments [7]. However, over the past years, additional 
studies and analyses were performed on the previously published data, pinpointing several pitfalls in the WHI study. It was concluded that the formulations of the HRT used, the time since the onset of menopause and the age at the initiation of treatment appeared to be important factors in affecting the clinical outcome. Hence, the current recommendations by the North American Menopause Society issued in 2017 specified that the clearest benefit of hormone therapy is for the treatment of vasomotor symptoms and prevention of bone loss for those at elevated risk aged younger than 60 years or within 10 years of menopause onset, if there are no contraindications $[8,9]$.

With the changing data concerning HRT use and its safety, research has become abundant on the knowledge and attitudes of women regarding HRT. Recently a study was published by Hamid et al. in the United Arab Emirates showing that most women had a poor knowledge regarding menopause, $35 \%$ did not use treatment for symptomatic relief, and only $27 \%$ had a good knowledge about HRT [10]. Chinese women, on the other hand, who had good knowledge about menopause but poor knowledge about HRT think that menopausal symptoms should not be treated [11]. Other reports mentioned that 40 to $83 \%$ of patients have ceased using HRT after the WHI study in other studied populations [12].

Such surveys are absent amongst the perimenopausal and menopausal Lebanese population. We aim through this survey to assess the readiness of Lebanese women to use HRT in managing menopausal symptoms when needed, irrespective of their current menopausal status. We also target to highlight the factors affecting this willingness and thus improve the counseling and the clinical outcome of the patients. An additional objective of this survey is to define the extent of impact of the WHI study on people's attitudes towards HRT.

\section{Methods}

A clinic-based cross-sectional study using a survey was offered to women coming to the women's health center at the American University of Beirut Medical Center (AUBMC) from October $1^{\text {st }}, 2017$, till March 31 ${ }^{\text {st }}, 2018$. Women aged 40 years and above were approached by the research team, and after explaining the aim of our study and taking the verbal consent, they were offered the questionnaire to fill without any identifiers. The questionnaire available in the Arabic language was previously tested on 15 participants to ensure that it was legible and comprehensive.

The sample size was determined based on comparing 2 independent proportions: women above the age of 40 years old and the percentage of menopausal women experiencing menopausal symptoms. The percentage of Lebanese women aged above 40 years old according to the 2015 population statistics was estimated to be around $15.3 \%$ of the female population (World Population Pyramid, 2015). As for the menopausal experience, around $50 \%$ of menopausal Lebanese women will experience at least one menopausal symptom (Obermeyer, Ghorayeb, and Reynolds 1999). According to these 2 proportions, the calculated sample size would be 56 . If we estimate a response rate of $40 \%$, the number of patients to be approached is 140 with a power of $80 \%$ and a significance level of $p<0.05$.

The questionnaire contained questions concerning different aspects of the patient's sociodemographic characteristics, parity, previous history of contraception use, menopausal status and its duration, and the menopausal symptoms. The second part of the questionnaire addressed their knowledge of HRT, including previous use, the indication for the initiation of HRT treatment and its duration, reasons behind the refusal or the cessation of the treatment, and whether they received proper counseling concerning the HRT. The last section addressed their knowledge of the WHI study results and whether it affected their decision-making when receiving HRT.

Data were described as number and percent for categorical variables, whereas the mean and standard deviation $( \pm \mathrm{SD})$ was calculated for continuous ones. Association with knowledge and attitude of HRT was assessed by the Pearson chi-square test for categorical variables, whereas Student's $t$ test was used for continuous ones. To identify predictors of knowledge and attitude of HRT, multivariate logistic regression was performed considering the variables that were found to be statistically significant at the bivariate level, where the $p$ value for entry was 0.05 and that for removal from the model was 0.10 . Results are presented as odds ratios (ORs) and their corresponding 95\% confidence intervals (CIs). The answers to the knowledge questions were specified on a 5 point Likert scale, ranging from "strongly disagree" to "strongly agree." An answer was considered correct when the subject agreed with a correct statement or disagreed with an incorrect statement. Moreover, the Likert scale score was transformed to $0-100$. A score of 0 indicates wrong answer, whereas a score of 100 indicates a correct answer. This scoring system was implemented on questions inquiring about knowledge and an overall score including knowledge of respondents. For all statistical analyses performed, values with a $p$ value $\leq 0.05$ were considered statistically significant. The study was reviewed and accepted by the International Review Board (IRB) at the American University of Beirut.

\section{Results}

Out of the original sample (140), 123 subjects accepted to participate in the study (response rate $=87.8 \%$ ). Overall characteristics of study participants are presented in Table 1. The mean age of the respondents was $50.18 \pm 8.72$ years old. The majority of the participants were married (86.2\%), had at least one child $(85.2 \%)$, and had used oral contraceptive pills previously $(78.8 \%)$.

Table 2 presents overall characteristics of HRT, as well as the percent of knowledge about HRT. Seventy-three percent of the respondents had already heard about HRT with $57.9 \%$ supporting the use of HRT as a part of treatment for women; however, $47.9 \%$ did not know when one could start using HRT. Regarding the knowledge score, the overall mean score of the respondents had correct information about HRT was $63.89 \pm 13.47$. The correct answers to the proposed questions are presented in Supplementary Table 1. Half of the women were prescribed HRT as a part of their treatment (51.6\%); 
TABle 1: Demographic data.

\begin{tabular}{|c|c|c|}
\hline & & Total $N=123$ \\
\hline Age group & Mean $( \pm S D)$ & $50.18 \pm 8.72$ \\
\hline \multirow{2}{*}{ Number of children delivered } & None & $18(14.8)$ \\
\hline & At least one child & $104(85.2)$ \\
\hline \multirow{2}{*}{ Marital status } & Married & $106(86.2)$ \\
\hline & Not married & $17(13.8)$ \\
\hline \multirow{2}{*}{ Employment } & Employed & $56(49.6)$ \\
\hline & Unemployed & $57(50.4)$ \\
\hline \multirow{2}{*}{ Education } & School & $32(29.4)$ \\
\hline & University & $77(70.6)$ \\
\hline \multirow{2}{*}{ Smoking } & Nonsmoker & $89(78.1)$ \\
\hline & Smoker & $25(21.9)$ \\
\hline History of OCP use & Yes & $89(78.1)$ \\
\hline \multirow{2}{*}{ Medical history } & Yes & $53(44.2)$ \\
\hline & Premenopausal & $53(43.1)$ \\
\hline \multirow[t]{3}{*}{ Menstrual status } & Perimenopausal & $18(14.6)$ \\
\hline & Postmenopausal & $52(42.3)$ \\
\hline & Spontaneous & $41(78.8)$ \\
\hline \multirow[t]{6}{*}{ Type of menopause in the case of menopaused female } & Surgical intervention & $7(13.5)$ \\
\hline & Medical treatment & $4(7.7)$ \\
\hline & None & $5(7.5)$ \\
\hline & One symptom & $10(14.9)$ \\
\hline & Hot flashes & $4(6.0)$ \\
\hline & Mood swings & $1(1.5)$ \\
\hline \multirow[t]{5}{*}{ Menopausal symptoms } & Feeling more tired than usual & $1(1.5)$ \\
\hline & Weight gain & $1(1.5)$ \\
\hline & Vaginal dryness & $1(1.5)$ \\
\hline & Facial hair growth & $2(3.0)$ \\
\hline & More than 2 symptoms & $52(77.6)$ \\
\hline Menopause duration in years & Mean $( \pm \mathrm{SD})$ & $7.99 \pm 7.33$ \\
\hline
\end{tabular}

Values presented in parenthesis are in \%.

however, in only $36.7 \%$ of cases, the benefits and the side effects were discussed by the prescribing physician. Only $22.3 \%$ of the respondents were familiar with the NIH study either through TV programs or via the Internet $32.0 \%$, respectively). This knowledge encouraged $44 \%$ of the participants to either refuse or stop using HRT (Table 2). The variables that were significantly associated with whether the participants have heard about HRT before or not were found to menopausal status with a $p$ value of 0.05 and the fact that HRT was prescribed as a treatment with a $p$ value of 0.004 (Table 3). The variables that affected the attitude of the participants towards HRT significantly were the basic knowledge concerning HRT ( $p$ value, 0.02), namely, the belief that HRT reduces vasomotor symptoms and is good to prevent age-related symptoms with a $p$ value of 0.01 and 0.03 , respectively. When multivariate regression analysis was performed, it was found that the only significant predictor for having heard about HRT was having HRT prescribed as a part of treatment (OR (95\% CI): $3.52(1.49-8.31), p=0.004)$. On the other hand, employment status was found to be the significant predictor for the positive attitude towards HRT (OR (95\% CI): 2.84 (1.08-7.47), $p=0.03$ ).

\section{Discussion}

The transition between the reproductive age and the menopausal status is one of the highlights of a woman's life. This transition is accompanied with discomfort and unusual sensations making women dread it and view it as a negative move in life. HRT were developed to ease these changes that are associated with the hormonal imbalance as well as maintenance of women's health. Data concerning the safety of HRT were contradictory, especially with the publication of the WHI study; however, recent clarifications were published by scientific bodies and guidelines were set for HRT use $[5,8,13]$. The main limiting factor for HRT use in many parts of the world nowadays remains to be the knowledge and attitudes towards HRT in the general population.

Our survey revealed that $73 \%$ are familiar with the term HRT, and almost $64 \%$ had good knowledge about the effects of HRT. This contrasts the results found in the UAE [10] and Egypt [14], 2 Arab countries where only 27\% and 9\% had some knowledge about HRT, respectively. Poor knowledge was also documented in a UK study where more than half of the respondents lacked the familiarity about HRT [15]. Fiftyeight percent of our respondents believed that HRT is a good treatment option when indicated, however, that a lack of knowledge of when to start the treatment was noted in $47.9 \%$ of the responders. Similar rates of positive attitudes towards HRT use was noted in the UK [15], contrary to the UAE [10] and China [11]. The lack of knowledge of when to start the treatment most likely stems from the fact that physicians are not discussing the benefits and the side effects as well as the treatment options with the patients $[16,17]$. This is reflected 
TABLE 2: HRT knowledge.

\begin{tabular}{|c|c|c|}
\hline & & Total $N=123$ \\
\hline \multirow{2}{*}{ Heard about HRT before } & Yes & $90(73.2)$ \\
\hline & No & $33(26.8)$ \\
\hline \multirow{2}{*}{ HRT use in menopause } & Positive & $44(57.9)$ \\
\hline & Negative & $32(42.1)$ \\
\hline \multirow{6}{*}{ When women start HRT } & Before the onset of menopause & $8(6.6)$ \\
\hline & With the onset of menopause & $25(20.7)$ \\
\hline & One year after the onset of menopause & $3(2.5)$ \\
\hline & When symptoms appear & $10(8.3)$ \\
\hline & Do not know & $58(47.9)$ \\
\hline & Never & $17(14.0)$ \\
\hline HRT knowledge total score & Mean $( \pm S D)$ & $63.89 \pm 13.47$ \\
\hline HRT replaces the hormones that decrease during menopause & Mean $( \pm \mathrm{SD})$ & $64.29 \pm 25.79$ \\
\hline HRT reduces vasomotor symptoms & Mean $( \pm$ SD) & $70.78 \pm 22.36$ \\
\hline HRT decreases the risk of colon cancer & Mean $( \pm \mathrm{SD})$ & $54.24 \pm 22.86$ \\
\hline HRT decreases the risk of osteoporosis & Mean $( \pm S D)$ & $67.75 \pm 26.11$ \\
\hline HRT increases the risk of breast cancer & Mean $( \pm \mathrm{SD})$ & $65.30 \pm 25.36$ \\
\hline HRT increases the risk of uterine cancer & Mean $( \pm S D)$ & $61.72 \pm 25.18$ \\
\hline HRT increases the risk of heart disease & Mean $( \pm \mathrm{SD})$ & $48.53 \pm 22.03$ \\
\hline HRT increases the risk of having blood clots & Mean $( \pm S D)$ & $53.06 \pm 22.03$ \\
\hline HRT good solution & Mean $( \pm S D)$ & $69.40 \pm 22.48$ \\
\hline HRT good for preventing age & Mean $( \pm S D)$ & $61.72 \pm 25.18$ \\
\hline HRT prescription & Yes & $63(51.6)$ \\
\hline Doctor discusses the benefits and side effects & Yes & $18(36.7)$ \\
\hline \multirow{2}{*}{ Reason for using } & One cause & $12(46.2)$ \\
\hline & More than 2 causes & $14(53.8)$ \\
\hline \multirow[t]{2}{*}{ Symptoms improve } & Yes & $12(85.7)$ \\
\hline & Internet & $9(16.1)$ \\
\hline \multirow{4}{*}{ Source of information } & Doctor & $116(28.6)$ \\
\hline & Society & $19(33.9)$ \\
\hline & Side effects that you actually felt & $5(8.9)$ \\
\hline & More than one source & $7(12.5)$ \\
\hline \multirow{7}{*}{ Encourage treatment } & Strongly agree & $4(7.0)$ \\
\hline & Agree & $21(36.8)$ \\
\hline & Neutral & $14(24.6)$ \\
\hline & Disagree & $14(24.6)$ \\
\hline & Strongly disagree & $4(7.0)$ \\
\hline & Agree & $25(43.9)$ \\
\hline & Disagree & $32(56.1)$ \\
\hline \multirow{6}{*}{ Awareness of WHI source of awareness } & Yes & $27(22.3)$ \\
\hline & Internet & $8(32.0)$ \\
\hline & Environment & $3(12.0)$ \\
\hline & Doctor & $2(8.0)$ \\
\hline & TV program & $8(32.0)$ \\
\hline & More than one source & $4(16.0)$ \\
\hline \multirow{3}{*}{ Effect on decision } & Start HRT & $3(16.7)$ \\
\hline & Refuse or stop using HRT & $8(44.4)$ \\
\hline & Neutral & $7(38.9)$ \\
\hline
\end{tabular}

in our survey where only $36.7 \%$ of the participants had received proper counseling about the treatment from their prescribing physicians. Earlier studies performed in Lebanon in 1999 revealed that despite 40\% of Beirut-residing women seek medical advice for menopausal symptoms, only $15 \%$ actually use HRT as a treatment [18]. Another survey performed among Lebanese gynecologists in 2005 showed that after the NIH study publication, prescriptions of HRT decreased and around $70 \%$ did counsel their patients about the breast cancer risk associated with HRT while almost 7\% avoid counseling in order not to confuse their patients [19].
This finding contrasts with the low level of counseling found in our study. A possible explanation might be that the physicians are taking treatment decisions without involving the patients in the process possibly to avoid the confusion or the resilience to treatment initiation. On the other hand, a survey performed amongst German gynecologists revealed that the main obstacle towards HRT prescription is in fact patients' concerns stemming from poor media sources and disinformation [20]. As a matter of fact, only $22 \%$ of our respondents were aware of the NIH study results having Internet and TV programs as the main source of 
TABLE 3: Factors influencing the attitude towards HRT use.

\begin{tabular}{|c|c|c|c|c|}
\hline & & HRT u & se in menopause & \\
\hline & & Positive $N=44$ & Negative $N=32$ & $p$ value \\
\hline Age group & Mean $( \pm \mathrm{SD})$ & $50.12 \pm 9.40$ & $54.33 \pm 10.18$ & 0.14 \\
\hline & None & $4(9.3)$ & $4(12.5)$ & 0.72 \\
\hline & At least one child & $39(90.7)$ & $28(87.5)$ & \\
\hline Number of children delivered & None & $4(9.3)$ & $4(12.5)$ & 0.03 \\
\hline Number of children delivered & $1-2$ & $13(30.2)$ & $12(37.5)$ & \\
\hline & $3-4$ & $25(58.1)$ & $10(31.2)$ & \\
\hline & $>4$ & $1(2.3)$ & $6(18.8)$ & \\
\hline Maritol ctature & Married & $40(90.9)$ & $30(93.8)$ & 1.00 \\
\hline Marital status & Not married & $4(9.1)$ & $2(6.2)$ & \\
\hline & Employed & $24(60.0)$ & $11(39.3)$ & 0.09 \\
\hline Employment & Unemployed & $16(40.0)$ & $17(60.7)$ & \\
\hline & School & $10(26.3)$ & $9(31.0)$ & 0.67 \\
\hline Education & University & $28(73.7)$ & $20(69.0)$ & \\
\hline & Nonsmoker & $34(87.2)$ & $23(76.7)$ & 0.25 \\
\hline Smoking & Smoker & $5(12.8)$ & $7(23.3)$ & \\
\hline History of OCP use & Yes & $12(30.0)$ & $10(31.2)$ & 0.91 \\
\hline Medical history & Yes & $24(57.1)$ & $14(43.8)$ & 0.25 \\
\hline & Premenopausal & $19(43.2)$ & $12(37.5)$ & 0.84 \\
\hline Menstrual status & Perimenopausal & $4(9.1)$ & $4(12.5)$ & \\
\hline & Postmenopausal & $21(47.7)$ & $16(50.0)$ & \\
\hline & Spontaneous & $18(81.8)$ & $14(77.8)$ & 0.85 \\
\hline Type of menopause in the case of menopaused female & Surgical intervention & $2(9.1)$ & $3(16.7)$ & \\
\hline & Medical treatment & $2(9.1)$ & $1(5.6)$ & \\
\hline & None & $1(3.8)$ & $1(5.3)$ & 0.13 \\
\hline & One symptom & $7(26.9)$ & $1(5.3)$ & \\
\hline & Hot flashes & $3(11.5)$ & $0(0.0)$ & \\
\hline & Mood swings & $1(3.8)$ & $0(0.0)$ & \\
\hline Menopausal symptoms & Feeling more tired than usual & $0(0.0)$ & $0(0.0)$ & \\
\hline & Weight gain & $1(3.8)$ & $0(0.0)$ & \\
\hline & Vaginal dryness & $1(3.8)$ & $0(0.0)$ & \\
\hline & Facial hair growth & $1(3.8)$ & $1(5.3)$ & \\
\hline & More than 2 symptoms & $18(69.2)$ & $17(89.5)$ & \\
\hline Menopause duration & Mean $( \pm S D)$ & $8.85 \pm 8.62$ & $10.31 \pm 7.29$ & 0.63 \\
\hline Heard about HRT before & Yes & $42(95.5)$ & $28(87.5)$ & 0.20 \\
\hline HRT total score & Mean $( \pm$ SD $)$ & $67.02 \pm 10.92$ & $59.70 \pm 15.17$ & 0.02 \\
\hline HRT prescription & Yes & $25(58.1)$ & $23(71.9)$ & 0.22 \\
\hline & Internet & $2(9.5)$ & $4(19.0)$ & 0.03 \\
\hline & Doctor & $8(38.1)$ & $3(14.3)$ & \\
\hline Source of information & Society & $5(23.8)$ & $10(47.6)$ & \\
\hline & Side effects that you actually felt & $0(0.0)$ & $3(14.3)$ & \\
\hline & More than one source & $6(28.6)$ & $1(4.8)$ & \\
\hline & Strongly agree & $1(4.5)$ & $0(0.0)$ & 0.01 \\
\hline & Agree & $12(54.5)$ & $3(13.6)$ & \\
\hline & Neutral & $6(27.3)$ & $6(27.3)$ & \\
\hline Encourage treatment & Disagree & $2(9.1)$ & $10(45.5)$ & \\
\hline & Strongly disagree & $1(4.5)$ & $3(13.6)$ & \\
\hline & Agree & $13(59.1)$ & $3(13.6)$ & 0.002 \\
\hline & Disagree & $9(40.9)$ & $19(86.4)$ & \\
\hline Awareness of WHI & Yes & $14(32.6)$ & $6(19.4)$ & 0.21 \\
\hline & Internet & $4(30.8)$ & $2(33.3)$ & 0.59 \\
\hline & Environment & $3(23.1)$ & $0(0.0)$ & \\
\hline Source of awareness & Doctor & $0(0.0)$ & $1(16.7)$ & \\
\hline & TV program & $3(23.1)$ & $2(33.3)$ & \\
\hline & More than one source & $3(23.1)$ & $1(16.7)$ & \\
\hline & Start HRT & $2(22.2)$ & $0(0.0)$ & 0.79 \\
\hline Effect on decision & Refuse or stop using HRT & $4(44.4)$ & $3(60.0)$ & \\
\hline & Neutral & $3(33.3)$ & $2(40.0)$ & \\
\hline
\end{tabular}


information. This emphasizes the important role that media plays affecting people's attitudes.

The fact that our respondents were acquainted with HRT was significantly related to the actual menopausal status as well as having HRT prescribed as a treatment for the bothersome symptoms. These findings emphasize the role of primary care providers in the process of diagnosis and treatment of menopausal patients. Proper counseling becomes of utmost importance in order to provide the patients with the most suitable treatment. Since our respondents did highlight the influence of media/society in general on their information, it is only logical that the physicians should properly counsel the patients about the benefits and the possible side effects of the implemented treatment, making the patient participate in the treatment plan decision. When the attitude towards HRT was studied, we found that the employment status was a significant predictor of acceptance of HRT as a treatment modality.

This might be related to a higher financial income and having insurance coverage, as shown in the 1999 study where women having insurance coverage, despite being nonsignificant, were more likely to use HRT [18].

One of the main advantages of our study is that it is the first of its type in Lebanon. Having such results will help promote proper counseling and improve treatment outcomes in patients. The patients that were targeted included the pre, peri, and postmenopausal periods, which helps understand more the different approaches to counsel. It also showed the deficient role of the primary care providers when it comes to patient management, and thus the physicians should be encouraged to participate more in the counseling process to avoid the misinformation. Of the draw backs of this study, it was performed in a tertiary care center in the capital of Lebanon. Despite the fact that this center is visited by people from all the Lebanese regions, the sample of the participants in our survey might not be representative of the whole female Lebanese population.

\section{Conclusion}

Lebanese women are aware of HRT as a treatment option; however, a lack of both proper information and positive attitude towards HRT use was noted. Menopausal status and actual HRT prescription were defined as significant predictors of HRT awareness while employment status was the only predictor for the positive attitude towards HRT.

\section{Abbreviations}

HRT: Hormone replacement therapy

WHI: World Health Institute

AUBMC: American University of Beirut Medical Center.

\section{Data Availability}

Due to the sensitive nature of the questions asked in this study, the IRB team and survey respondents were assured that raw data would remain confidential and would not be shared. For further inquiries, the IRB team can be reached via the following e-mail: irb@aub.edu.lb.

\section{Conflicts of Interest}

The authors declare that there are no conflicts of interest.

\section{Authors' Contributions}

Anastasia Salame participated in the study design formation, data collection, and analysis as well as writing of the manuscript. Mohammad Jaffal and Fatin Khalifeh participated in the study design formation and data collection as well as writing of the manuscript. Dalia Khalife participated in the study design formation and statistical analysis as well as writing of the manuscript. Ghina Ghazeeri participated in the study design formation, data collection, and statistical analysis as well as writing of the manuscript and its review.

\section{Acknowledgments}

The authors would like to acknowledge Mrs. Manal Ayoub, a registered nurse at AUBMC. Mrs. Ayoub helped in patient recruitment.

\section{Supplementary Materials}

Supplementary Table 1: the correct statements to the HRTrelated general statements. (Supplementary Materials)

\section{References}

[1] J. A. Houck, "How to treat a menopausal woman: a history, 1900 to 2000," Current Womens Health Reports, vol. 2, no. 5, pp. 349-355, 2002.

[2] S. D. Harlow, M. Gass, J. E. Hall et al., "Executive summary of the stages of reproductive aging workshop + 10: addressing the unfinished agenda of staging reproductive aging," The Journal of Clinical Endocrinology \& Metabolism, vol. 97, no. 4, pp. 1159-1168, 2012.

[3] K. J. Lund, "Menopause and the menopausal transition," Medical Clinics of North America, vol. 92, no. 5, pp. 12531271, 2008.

[4] M. Tao, Y. Teng, H. Shao et al., "Knowledge, perceptions and information about hormone therapy (HT) among menopausal women: a systematic review and meta-synthesis," PLoS One, vol. 6, no. 9, Article ID e24661, 2011.

[5] J. Rossouw and E. Writing, “Group for the Women's Health Initiative Investigators. Risks and benefits of estrogen plus progestin in healthy postmenopausal women: principal results from the Women's Health Initiative randomized controlled trial," JAMA, vol. 288, pp. 321-333, 2002.

[6] American College of Obstetricians and Gynecologists, Guidelines for Women's Health Care, American College of Obstetricians and Gynecologists Women's Health Care Physicians, Washington, D.C., USA, 2002.

[7] US Preventive Services Task Force, "Hormone therapy for the prevention of chronic conditions in postmenopausal women: recommendations from the US Preventive Services Task Force," Annals of Internal Medicine, vol. 142, no. 10, p. 855, 2005.

[8] J. A. V. Pinkerton, F. S. Aguirre, J. Blake et al., "The 2017 hormone therapy position statement of the North American 
Menopause Society," Menopause, vol. 24, no. 7, pp. 728-753, 2017.

[9] P. F. Schnatz, "The 2017 hormone therapy position statement of The North American Menopause Society," Menopause, vol. 24, no. 7, pp. 728-753, 2017.

[10] S. Hamid, F. R. Al-Ghufli, H. A. Raeesi et al., "Women's knowledge, attitude and practice towards menopause and hormone replacement therapy: a facility based study in AlAin, United Arab Emirates," Journal of Ayub Medical College Abbottabad, vol. 26, no. 4, pp. 448-454, 2014.

[11] F. Jin, M. Tao, Y. Teng, H. Shao, C. Li, and E. Mills, "Knowledge and attitude towards menopause and hormone replacement therapy in Chinese women," Gynecologic and Obstetric Investigation, vol. 79, no. 1, pp. 40-45, 2015.

[12] R. Haimov-Kochman and D. Hochner-Celnikier, "Are there second thoughts about the results of the WHI study?" Acta obstetricia et gynecologica Scandinavica, vol. 85, no. 4, pp. 387-393, 2006.

[13] R. J. Baber, N. Panay, and A. Fenton, "2016 IMS Recommendations on women's midlife health and menopause hormone therapy," Climacteric, vol. 19, no. Supp.2, pp. 109150, 2016.

[14] I. Loutfy, F. Abdel Aziz, N. I. Dabbous, and M. H. Hassan, "Women's Perception and experience of menopause: a community-based study in Alexandria, Egypt," EMHJ-Eastern Mediterranean Health Journal, vol. 12, no. 2, pp. S193-S106, 2006.

[15] H. K. Sinclair, C. M. Bond, and R. J. Taylor, "Hormone replacement therapy: a study of women's knowledge and attitudes," British Journal of General Practice, vol. 43, no. 374, pp. 365-370, 1993.

[16] A. Weissmann-Brenner, B. Brenner, J. Sulkes et al., "Women gynecologists' attitude toward their own health," Medical Science Monitor, vol. 16, no. 4, pp. PH35-PH39, 2010.

[17] H. S. Malik, "Knowledge and attitude towards menopause and hormone replacement therapy (HRT) among postmenopausal women," Therapy, vol. 11, p. 12, 2008.

[18] C. M. Obermeyer, F. Ghorayeb, and R. Reynolds, "Symptom reporting around the menopause in Beirut, Lebanon," Maturitas, vol. 33, no. 3, pp. 249-258, 1999.

[19] A. H. Nassar, H. M. A. Essamad, J. T. Awwad, N. G. Khoury, and I. M. Usta, "Gynecologists' attitudes towards hormone therapy in the post "Women's Health Initiative" study era," Maturitas, vol. 52, no. 1, pp. 18-25, 2005.

[20] K. J. Buhling, F. S. G. v. Studnitz, A. Jantke, C. Eulenburg, and A. O. Mueck, "Attitude of German gynecologists towards prescribing HRT before and after the WHI study," Climacteric, vol. 15, no. 4, pp. 326-331, 2012. 